\title{
Psychological predictors of change in the number of musculoskeletal pain sites among Norwegian employees: a prospective study
}

\author{
Jan Olav Christensen ${ }^{1 *} \mathbb{D}$, Sissel Johansen ${ }^{2}$ and Stein Knardahl ${ }^{1}$
}

\begin{abstract}
Background: The pathogenesis of syndromes of widespread musculoskeletal pain remains an enigma. The present study sought to determine if psychological states, job satisfaction, pain intensity, and sleep problems contributed to the spread and decline of the number of musculoskeletal pains.

Methods: A sample of 2989 Norwegian employees completed a questionnaire at baseline and follow-up 2 years later. Data were analyzed with multinomial and ordinal logistic regression analyses to determine effects on direction and degree of change of number of pain sites (NPS).

Results: After adjustment for sex, age, skill level, and number of pain sites at baseline, increases in the number of pain sites from baseline to follow-up were predicted by emotional exhaustion, mental distress, having little surplus, feeling down and sad, sleep disturbances, and intensity of headache. Decreases were predicted by low levels of emotional exhaustion, mental distress, sleep disturbances, restlessness, and lower intensity of headache, neck pain, shoulder pain, and back pain. Higher numbers of pain sites at baseline were associated with reduction of number of pain sites and lower likelihood of spread. Some factors that did not predict whether decrease or increase occurred were nevertheless associated with the degree of decrease (depression, anxiety, having surplus, self-efficacy) or increase (anxiety).

Conclusions: Several psychological and physiological factors predicted change in the number of pain sites. There is a need for further investigations to identify possible mechanisms by which psychological and behavioral factors propagate the spread of pain.
\end{abstract}

\section{Background}

The incidence of chronic musculoskeletal pain in the general population is high $[1,2]$, and musculoskeletal disorders are the most prevalent health complaints among European employees [3]. Among individuals with musculoskeletal pain, reporting pain in five or more sites has been found to be more common than reporting pain in one site only [4]. Multi-site pain has been found to predict sickness absence [5] and work ability [6]. It has been suggested that counting the concurrent number of pain sites (NPS) may serve as a method of identifying risk of disability $[6,7]$.

\footnotetext{
* Correspondence: joc@stami.no

${ }^{1}$ Department of Work Psychology and Physiology, The National Institute of Occupational Health, Oslo, Norway

Full list of author information is available at the end of the article
}

Hypotheses of the pathogenesis of spread of pain seem to focus mainly on (i) alterations of nociceptive pathways of the central nervous system, e.g. "central sensitization", the definition of which is rather imprecise $[8,9]$, or (ii) psychological mechanisms like attention to somatic sensations (e.g. perceptual amplification [10]). The objective of the present study was to determine the contribution of psychological factors commonly associated with pain to subsequent spread or reduction of the number of musculoskeletal pain sites reported by employees in a working population.

Mental distress, anxiety, and depression are associated with chronic pain (see e.g. [11]), and depressive symptoms seem to contribute to the development and persistence of chronic musculoskeletal pain [12, 13]. Therefore, we sought to determine the contribution from several 
aspects of emotional state to changes in NPS. Catastrophizing seems related to some chronic pain states [14]. We sought to determine if the opposite of pessimistic attitudes may play a role, hence we included optimism and general self-efficacy. Sleep disturbance is one of the most prevalent co-morbid problems among pain patients $[15,16]$ and has been found to contribute to both onset and amplification of pain [17]. Sleep restriction may increase risk of next-day pain [18]. A 14-year follow-up study demonstrated that initial multi-site pain, sleep quality, sex, age and educational level were risk factors for an increased number of pain in a Norwegian county population [19]. We sought to elucidate the role of sleep disturbances and tiredness for spread of pain. Finally, we sought to determine if the intensity of pain in specific sites increased the risk of more widespread pain.

In short, the present study examined a large sample of Norwegian working individuals to determine whether psychological states and traits, sleep problems, and pain intensity predicted increases and decreases in the number of painful anatomic sites over a 2 years period.

\section{Methods}

Design

The study was a two-wave prospective full-panel study. All variables were measured by web-based self-report questionnaires at baseline and follow-up 2 years later.

\section{Subjects}

Subjects were recruited from Norwegian companies that volunteered to participate. Baseline data were gathered from 2004 to 2011, follow-up data from 2006 to 2013. The follow-up period was approximately 2 years for all respondents (mean: 24 months, SD: 2.8 months, range: 18-36 months).

The current study was part of a larger project measuring a range of work- and health factors. Sixty-three organizations were included in this study, with a variety of job types from the private and public sector (see Table 1). The companies received reports and presentations of results as a tool for organizational development in return for participation and making the data available for research. For more detailed description of procedures, see [20].

Employees and management were first informed at the organizational level before all employees received a letter with an invitation and information about the survey. The letter included a personal access code to the webquestionnaire or a paper version of the questionnaire with a pre-stamped return envelope.

Only respondents who answered whether they had pain or not in all five pain sites listed in the questionnaire, at both time points, were included. A total of 10274 employees were invited at both the first (T1) and the second survey (T2), of which 6198 (60.3\%) answered all five pain region questions at $\mathrm{T} 1$. The primary interest of the study pertained to the course of existing pain problems. Therefore, respondents who reported no pain in any anatomic site at $\mathrm{T} 1$ were excluded from analyses of pain change direction, as this group's report of pain at T2 may represent onset and not spread of pain. In addition, a decrease in the number of pain sites would not be possible for this group. Likewise, subjects reporting pain in all sites at T1 were excluded, as pain spread would not be possible for this group. Thus, the final main sample comprised 2989 subjects that reported 1-4 pain sites at $\mathrm{T} 1$ and completed all five pain items at both time points (see Fig. 1 and Table 2).

\section{Ethics}

The study was approved by the Norwegian Data Inspectorate and the Regional Committees for Medical and Health Research Ethics (REK) in Norway and conducted in accordance with the World Medical Association Declaration of Helsinki. All study participants provided informed consent. The consent procedure was approved by the Data Inspectorate of Norway and REK. Data were stored and analyzed in accordance with procedures designed to ensure the anonymity of participants.

\section{Outcome: change of number of pain sites}

Musculoskeletal pain was measured by reported intensity of pain in five anatomic sites during 4 weeks prior to answering the questionnaire; neck, shoulder, back, arm, and leg [21]. Each question was phrased: "Have you been troubled by... (e.g. neck pain) the last 4 weeks? Response alternatives were: 1) "not troubled", 2) "a little troubled", 3) "rather intensely troubled" and 4)" very intensely troubled". In Norwegian, the wording "troubled by" is a common way of expressing symptoms. Number of pain sites scales for baseline (NPS T1) and follow-up (NPS T2) were constructed. First, each question (i.e. region) was dichotomized to " $0=$ not troubled" and " $1=$ troubled". Then the NPS scales were constructed by summing these five items.

In order to capture the direction as well as the degree of change in NPS different variables were constructed based on the difference between T1 and T2 NPS.

First, a three-category variable was constructed to reflect stability, decrease, and increase of NPS from T1 to T2. Stability was operationalized as reporting the same number of pain sites at T1 and T2. Decrease was defined as reporting at least one pain site less at $\mathrm{T} 2$, and increase as reporting at least one pain site more at $\mathrm{T} 2$ than at $\mathrm{T} 1$. No inherent order was assumed among these three categories, hence the variable was treated as nominal.

The degree of change was assessed separately for the three groups defined by the change direction variable. Thus, for those experiencing increase and decrease the degree of 
Table 1 Baseline characteristics of all invited subjects, responders at $T 1^{\mathrm{a}}$, responders at both $\mathrm{T} 1$ and $\mathrm{T} 2^{\mathrm{b}}$, and the final prospective sample after exclusionc

\begin{tabular}{|c|c|c|c|c|c|c|c|c|}
\hline & \multirow{2}{*}{$\begin{array}{l}\text { All invited } \\
(N=10274) \\
N(\%)\end{array}$} & \multirow{2}{*}{$\begin{array}{l}\text { Responders at } \\
\text { T1 }(n=6198) \\
N(\%)\end{array}$} & \multicolumn{2}{|c|}{$\begin{array}{l}\text { Association with } \\
\text { non-response at } \mathrm{T} 1\end{array}$} & \multirow{2}{*}{$\begin{array}{l}\text { Responders at both } \\
\text { T1 and T2 }(n=4204) \\
N(\%)\end{array}$} & \multicolumn{2}{|c|}{$\begin{array}{l}\text { Association with } \\
\text { dropout after } T 1^{d}\end{array}$} & \multirow{2}{*}{$\begin{array}{l}\text { Prospective sample } \\
\text { after exclusion } \\
(n=2989) \\
N(\%)\end{array}$} \\
\hline & & & OR & $95 \% \mathrm{Cl}$ & & OR & $95 \% \mathrm{Cl}$ & \\
\hline \multicolumn{9}{|l|}{ Sex } \\
\hline Male & 3852 (37.5) & 2405 (38.8) & ref & - & $1681(40.0)$ & ref & - & 1161 (38.8) \\
\hline Female & $6422(62.5)$ & $3793(61.2)$ & 1.16 & {$[1.07-1.26]^{* *}$} & $2523(60.0)$ & 1.02 & [0.89-1.17] & $1828(61.2)$ \\
\hline \multicolumn{9}{|l|}{ Age } \\
\hline$<30$ & $796(7.7)$ & $451(7.3)$ & ref & - & $269(6.4)$ & ref & - & $196(6.6)$ \\
\hline $30-39$ & $2519(24.5)$ & $1556(25.1)$ & 0.81 & {$[0.69-0.95]^{*}$} & $1048(24.9)$ & 0.82 & [0.63-1.07] & $733(24.5)$ \\
\hline $40-49$ & 3118 (30.3) & 1933 (31.2) & 0.80 & {$[0.68-0.94]^{* *}$} & 1330 (31.6) & 0.72 & {$[0.55-.95]^{*}$} & $970(32.5)$ \\
\hline $50-59$ & $2973(28.9)$ & 1775 (28.6) & 0.89 & {$[0.76-1.04]$} & $1230(29.3)$ & 0.74 & {$[0.56-.97]^{*}$} & $870(29.1)$ \\
\hline$>59$ & $868(8.4)$ & $483(7.8)$ & 1.06 & [0.87-1.28] & $327(7.8)$ & 0.83 & {$[0.60-1.17]$} & $220(7.4)$ \\
\hline \multicolumn{9}{|l|}{ Marital status } \\
\hline Not married & & $618(13.1)$ & & & 444 (13.8) & ref & - & 309 (13.5) \\
\hline Married & & $2893(61.2)$ & & & 1982 (61.6) & 1.21 & [0.99-1.49] & 1410 (61.6) \\
\hline Cohabiting & & 764 (16.2) & & & $499(15.5)$ & 1.32 & [1.04-1.67] & $370(16.2)$ \\
\hline Widowed & & $62(1.3)$ & & & $40(1.2)$ & 1.40 & {$[0.78-2.51]$} & $26(1.1)$ \\
\hline Divorced & & $313(6.6)$ & & & $203(6.3)$ & 1.34 & [0.98-1.82] & $137(6.0)$ \\
\hline Separated & & $75(1.6)$ & & & $47(1.5)$ & 1.47 & [0.88-2.46] & $38(1.7)$ \\
\hline Missing data & & $1473-$ & & & $989-$ & - & - & $699-$ \\
\hline \multicolumn{9}{|l|}{ Occupation } \\
\hline Professionals & & $1757(29.0)$ & & & 1283 (31.3) & ref & - & 904 (30.9) \\
\hline $\begin{array}{l}\text { Armed forces and } \\
\text { unspecified }\end{array}$ & & $32(0.5)$ & & & $20(0.5)$ & 1.78 & [0.83-3.82] & $15(0.5)$ \\
\hline $\begin{array}{l}\text { Legislators, senior officials } \\
\text { and managers }\end{array}$ & & $587(9.7)$ & & & $464(11.3)$ & 0.81 & {$[0.62-1.05]$} & $307(10.5)$ \\
\hline $\begin{array}{l}\text { Technicians and associate } \\
\text { professionals }\end{array}$ & & $2040(33.7)$ & & & $1323(32.3)$ & 1.66 & {$[1.41-1.95]^{* *}$} & $954(32.6)$ \\
\hline Clerks & & $501(8.3)$ & & & $313(7.6)$ & 1.73 & {$[1.36-2.21]^{* *}$} & $244(8.3)$ \\
\hline $\begin{array}{l}\text { Service workers and } \\
\text { shop and market sales } \\
\text { workers }\end{array}$ & & $979(16.2)$ & & & $605(14.8)$ & 1.70 & {$[1.40-2.05]^{* *}$} & $443(15.2)$ \\
\hline $\begin{array}{l}\text { Skilled agricultural } \\
\text { and fishery workers }\end{array}$ & & $2(0.0)$ & & & $1(0.0)$ & 2.85 & {$[0.17-46.49]$} & $0(0.0)$ \\
\hline $\begin{array}{l}\text { Craft and related } \\
\text { trades workers }\end{array}$ & & $67(1.1)$ & & & $43(1.0)$ & 2.11 & {$[1.19-3.75]^{*}$} & $29(1.0)$ \\
\hline $\begin{array}{l}\text { Plant and machine operators } \\
\text { and assemblers }\end{array}$ & & $8(0.1)$ & & & $3(0.1)$ & 4.86 & {$[0.81-29.35]$} & $2(0.1)$ \\
\hline Elementary occupations & & $76(1.3)$ & & & $45(1.1)$ & 2.10 & {$[1.26-3.50]^{* *}$} & $26(0.9)$ \\
\hline Missing data & & $149-$ & & & $104-$ & - & - & $65-$ \\
\hline \multicolumn{9}{|l|}{ Skill level } \\
\hline$>15$ years & & $1757(29.0)$ & & & $1283(31.3)$ & ref & - & $904(30.9)$ \\
\hline $13-15$ years & & $2040(33.7)$ & & & $1323(32.3)$ & 1.66 & {$[1.41-1.95]^{* *}$} & $954(32.6)$ \\
\hline $10-12$ years & & $1557(25.7)$ & & & $965(23.5)$ & 1.73 & {$[1.46-2.05]^{* *}$} & $718(24.6)$ \\
\hline$<10$ years & & $76(1.3)$ & & & $45(1.1)$ & 2.10 & {$[1.26-3.50]^{* *}$} & $26(0.9)$ \\
\hline Unspecified & & $619(10.2)$ & & & $484(11.8)$ & 0.86 & {$[0.67-1.10]$} & $322(11.0)$ \\
\hline Missing data & & 149 - & & & $104-$ & - & - & $65-$ \\
\hline
\end{tabular}


Table 1 Baseline characteristics of all invited subjects, responders at $\mathrm{T}^{\mathrm{a}}{ }^{\mathrm{a}}$, responders at both $\mathrm{T} 1$ and $\mathrm{T} 2^{\mathrm{b}}$, and the final prospective sample after exclusion ${ }^{c}$ (Continued)

\begin{tabular}{|c|c|c|c|c|c|}
\hline \multicolumn{6}{|c|}{ Number of pain sites at $\mathrm{T} 1$} \\
\hline 0 & $1446(23.3)$ & $1001(23.8)$ & ref & - & - \\
\hline 1 & $1359(21.9)$ & $962(22.9)$ & 0.86 & {$[0.71-1.04]$} & $962(32.2)$ \\
\hline 2 & $1299(21.0)$ & $884(21.0)$ & 0.99 & {$[0.82-1.20]$} & $884(29.6)$ \\
\hline 3 & $1082(17.5)$ & $706(16.8)$ & 1.13 & {$[0.92-1.38]$} & $706(23.6)$ \\
\hline 4 & $680(11.0)$ & $437(10.4)$ & 1.13 & {$[0.90-1.41]$} & $437(14.6)$ \\
\hline 5 & $332(5.4)$ & $214(5.1)$ & 1.21 & [0.90-1.63] & - \\
\hline
\end{tabular}

${ }^{*} p<0.05,{ }^{* *} p<0.01$

${ }^{a}$ Response at T1 was defined as having completed all five pain items at T1

${ }^{\mathrm{b}}$ Response at both $\mathrm{T} 1$ and $\mathrm{T} 2$ was defined as having completed all pain items at both $\mathrm{T} 1$ and $\mathrm{T} 2$

'The final prospective sample comprised employees that participated at both T1 and T2 and that reported at least one but no more than four pain sites at T1

${ }^{\mathrm{d}}$ Association with dropout was computed among $\mathrm{T} 1$ responders by multivariable logistic regressions with all predictors included simultaneously, except skill level and occupation which were entered separately since they were different categorizations of the same variable. "Dropout" was defined as responding at T1, but not volunteering information about all five studied pain sites at $\mathrm{T} 2$

change was operationalized as the number of pain sites more or less at $\mathrm{T} 2$ than at $\mathrm{T} 1$. For those reporting the same number of pain sites at $\mathrm{T} 1$ and $\mathrm{T} 2$ the outcome variable was the number of pain sites that they reported.

\section{Predictors}

Pain intensity of each musculoskeletal site was measured as described above. Additionally, headache, tiredness,

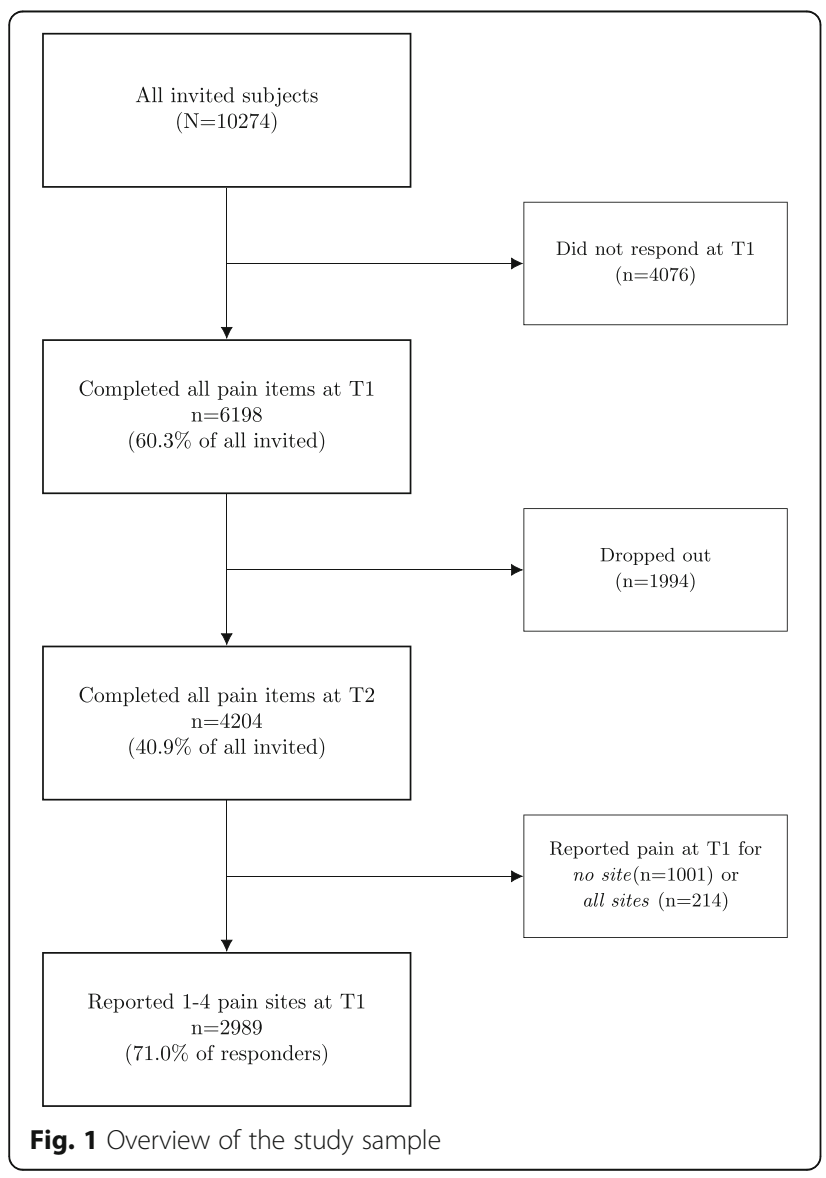

restlessness, depression, and anxiety were measured with equivalent single items and the same response categories.

Emotional exhaustion was measured with six items from the Copenhagen Burnout Inventory [22]; how often... "do you feel tired?", "are you physically exhausted?", "are you emotionally exhausted?", "do you think 'I can't stand anymore?", "do you feel worn out", and "do you feel weak and susceptible to diseases". Response alternatives were " $1=$ never/almost never", " 2 = a couple of times per month", " $3=$ once or twice a week", " $4=$ three to four times a week", and " 5 = (almost) every day". Items were combined into one scale $(\alpha=0,83)$. The average score was estimated and the variable was recoded: "1.00-1.50" set to "1", "1.51-2.50" set to "2", "2.51-3.50" set to "3", "3.51-4.50" set to " 4 " and " $4.51-5.00$ " set to " 5 ".

Psychological well-being was measured with two single items: "The last 4 weeks, how often have you....." a)" had a lot of surplus" and b) "felt down and sad". Response categories were " $1=$ all the time", " $2=$ almost all the time", " 3 = much of the time", " $4=$ some of the time", " $5=$ a bit of the time", and " $6=$ not at all". To aid interpretation, the items were reversed so high levels reflected high perceived surplus and feelings of sadness.

Sleep disturbance was measured with two separate items: "Have you noticed the following problems the last 4 weeks": a) "difficulties with sleeping" and b)" disturbed/restless sleep". Response categories were " $1=$ zero", " $2=1-3$ times per month", " $3=1-2$ times a week", " $4=3-5$ times a week" and " $5=6-7$ times a week". These items were combined into one scale $(\alpha=0,82)$. The average score was estimated, and the variable recoded for analyses with categorical predictors: "1.00-1.50" set to " 1 ", "1.51-2.50" set to " 2 ", "2.51-3.50" set to " 3 ", "3.51-4.50" set to " 4 ", and" $4,51-5,00$ " set to " 5 ".

Global job satisfaction was assessed with one question: "All things considered, how satisfied are you with your 
Table 2 Separate multinomial logistic regressions relating psychological factors and pain intensities at T1 to number of pain sites (NPS) decrease (NPS T1 > NPS T2) and increase (NPS T1 < NPS T2) compared with reporting a stable number of pain sites (NPS T1 = NPS T2)

\begin{tabular}{|c|c|c|c|c|c|}
\hline \multirow[t]{2}{*}{ T1 Predictor } & \multirow[t]{2}{*}{$N$} & \multicolumn{2}{|c|}{$\begin{array}{l}\text { Decrease NPS } \\
(\mathrm{T} 1>\mathrm{T} 2)\end{array}$} & \multicolumn{2}{|c|}{$\begin{array}{l}\text { Increase NPS } \\
(\mathrm{T} 1<\mathrm{T} 2)\end{array}$} \\
\hline & & OR & $95 \% \mathrm{Cl}$ & OR & $95 \% \mathrm{Cl}$ \\
\hline Emotional exhaustion & 2644 & 0.81 & {$[0.69-0.95]^{* *}$} & 1.34 & {$[1.15-1.57]^{* * *}$} \\
\hline Mental distress (HSCL) & 2752 & 0.69 & {$[0.54-0.89]^{* * *}$} & 1.64 & {$[1.28-2.10]^{* * *}$} \\
\hline Depression (single item) & 2912 & 0.90 & {$[0.76-1.05]$} & 1.16 & {$[0.99-1.37]$} \\
\hline Anxiety (single item) & 2909 & 0.86 & {$[0.66-1.11]$} & 1.09 & {$[0.84-1.41]$} \\
\hline \multicolumn{6}{|l|}{ Psychological well-being } \\
\hline "Had a lot of surplus" & 2814 & 1.02 & {$[0.95-1.10]$} & 0.87 & {$[0.80-0.95]^{* * *}$} \\
\hline "Felt down and sad" & 2808 & 0.98 & {$[0.88-1.09]$} & 1.18 & {$[1.06-1.31]^{* * *}$} \\
\hline Dispositional optimism & 2858 & 1.08 & {$[0.94-1.25]$} & 0.94 & {$[0.81-1.09]$} \\
\hline General self-efficacy & 2862 & 0.97 & {$[0.82-1.14]$} & 1.05 & {$[0.88-1.26]$} \\
\hline Job satisfaction & 2608 & 1.05 & {$[0.90-1.22]$} & 0.97 & {$[0.82-1.15]$} \\
\hline Sleep disturbance & 2801 & 0.87 & {$[0.79-0.96]^{* * *}$} & 1.19 & {$[1.07-1.31]^{* * *}$} \\
\hline Tiredness & 2919 & 0.82 & {$[0.73-0.93]^{* * *}$} & 1.24 & {$[1.09-1.40]^{* * *}$} \\
\hline Restlessness & 2915 & 0.80 & {$[0.69-0.92] * * *$} & 1.08 & {$[0.93-1.25]$} \\
\hline \multicolumn{6}{|l|}{ Pain intensity } \\
\hline Headache & 2921 & 0.81 & {$[0.72-0.91]^{* * *}$} & 1.17 & {$[1.04-1.32]^{* *}$} \\
\hline Neck pain & 2924 & 0.64 & {$[0.56-0.73]^{* * *}$} & 1.02 & {$[0.89-1.17]$} \\
\hline Shoulder pain & 2924 & 0.78 & {$[0.68-0.89]^{* * *}$} & 0.98 & {$[0.85-1.12]$} \\
\hline Arm pain & 2924 & 1.09 & {$[0.95-1.25]$} & 0.97 & {$[0.83-1.14]$} \\
\hline Leg pain & 2924 & 1.06 & {$[0.93-1.21]$} & 1.03 & {$[0.88-1.19]$} \\
\hline Back pain & 2924 & 0.85 & {$[0.76-0.96]^{* *}$} & 1.06 & {$[0.93-1.20]$} \\
\hline Number of pain sites at $\mathrm{T} 1$ & 2924 & 1.33 & {$[1.22-1.45]^{* * *}$} & 0.79 & {$[0.72-0.87]^{* * *}$} \\
\hline
\end{tabular}

${ }^{*} p<0.05,{ }^{* *} p<0.01,{ }^{* * *} p<0.001$

Note: Subjects that reported either no pain sites or five pain sites at T1 were excluded since they could not experience decrease or increase of NPS, correspondingly. All regressions were adjusted for sex, age group, skill level, and T1 NPS

job?" with alternatives " $1=$ very dissatisfied", "2 = dissatisfied", " 3 = satisfied" and " $4=$ very satisfied". The scale was reversed for the analyses.

Optimism was measured with three items from the "Revised Life Orientation Test (LOT-R)" [23]: "In uncertain times, I usually expect the best", "I hardly ever expect things to go my way" (reversed item), "overall, I expect more good things to happen to me than bad". Response categories were " 1 = strongly disagree", " $2=$ disagree", " $3=$ neutral", " $4=$ agree" and " $5=$ strongly agree". Items were combined into one scale $(\alpha=0,61)$. The average score was estimated, and the variable recoded: " $1.00-1.50$ " set to " 1 ", "1.51-2.50" set to " 2 ", "2.51-3.50" set to " 3 ", "3.51-4.50" set to "4", and" $4,51-5,00$ " set to " 5 ".

Due to a low number of employees reporting "strongly disagree" and "disagree" the two first categories of the categorized measure were collapsed.

General self-efficacy was measured with three items from the instrument developed by Schwarzer and Jerusalem [24]: "I can solve most problems if I just make an effort", "If I am in trouble, I usually find a solution", "No matter what happens; I am usually capable of handling it". Alternatives were " $1=$ strongly disagree", " $2=$ disagree", " $3=$ neutral", " $4=$ agree" and " $5=$ strongly agree". The items were combined into one scale $(\alpha=$ 0,83 ). Since very few employees reported low selfefficacy the scale was reversed before analyses to maximize statistical power in categorical analyses with the first category as reference.

Mental distress during the last week was measured by ten items from the Hopkins Symptom Checklist (HSCL10) [25]. Example items are "Feeling tense or keyed up" and "A feeling of hopelessness about the future", rated on a four-point scale ranging from " $1=$ have not experienced it" to " $4=$ very much". HCSL-10 has been demonstrated to be a valid and reliable measure of psychological distress [26]. Items were combined into one scale $(\alpha=0,86)$. The average score was estimated and the variable recoded: "1.00-1.50" set to " 1 ", "1.512.50 " set to "2", "2.51-3.50" set to " 3 ", "3.51-4.00" set to "4". Due to a small number of subjects in the last category, "3" and "4" were collapsed. 
Age, sex and skill level were included in all multivariable regressions as possible confounders. Age was classified into age groups: "<30", "30-39", "40-49", "50-59" and " $>59$ ". Skill levels were derived from information reported by the companies. Classifications were based on the International Standard Classification of Occupations (ISCO-88), which is a tool to organize jobs into groups according to the tasks and duties typically undertaken in the job. Educational level or equivalent working experience required for the job is also reflected by the ISCO-88, according to the International Standard Classification of Education (ISCED). Skill level categories thus denote occupations that normally require $(1)=$ first or postgraduate university degree or college exams of similar level ( $>16$ years of education); $(2)=1-3$ years of college/ university education (13-15 years); $(3)=1-3$ years of secondary education (10-12 years); (4) = primary education $(<9$ years $)$ and $(5)=$ unspecified competence level (i.e. occupations with no formally required education).

\section{Statistical analyses}

All statistical analyses were conducted with $R$, version 3.3.1 [27].

Non-response analyses were conducted by multivariable binary logistic regressions. The odds of nonresponse (i.e. failing to answer all pain items) at baseline were computed based on sex and age. Next, the risk of attrition bias was assessed by computing the odds of being a non-responder at the second survey among those who responded at T1. For the attrition analysis, sex, age, marital status, skill level, and number of pain sites were entered as predictors in a multivariable logistic regression.

In order to study the relationships of the included factors with direction of change of NPS, multinomial regressions were conducted to determine relationships between baseline predictors and NPS change. First, regressions were conducted separately for each predictor adjusted for age group, sex, skill level, and T1 NPS. Then, all predictors were entered into one regression to determine any unique associations between predictors and direction of change after mutual adjustment. The multinomial regressions expressed the effect of the predictors on the likelihood of experiencing pain increase or decline when compared with experiencing stability in NPS, controlled for sex, age, skill level and initial NPS.

The association of predictors with the degree of change in NPS was assessed by running regression separately for the groups that reported decrease and increase of NPS to predict the number of pain sites more or less at T2. Since the $\triangle$ NPS variable was skewed ordinal logistic regressions were conducted. Ordinal regression expresses the change in odds of having a higher level of the outcome (i.e. $\triangle$ NPS) per unit change of the predictor, assuming that the difference in odds is the same for all cut points of the outcome variable.

Regressions of NPS change direction were also conducted with predictors categorized, to reflect the effects of specific levels of the predictor. Likelihood ratio tests (LRTs) were computed to determine whether models with categorized predictors represented a statistically significant improvement over the corresponding models with continuous predictors, which would suggest the presence of non-linear effects such as e.g. threshold effects.

\section{Results}

At baseline, 23.3\% of subjects reported no pain, 21.9\% reported one pain site, $21 \%$ reported two sites, $17.5 \%$ three sites, $11 \%$ four sites, and $5.4 \%$ reported five pain sites (Table 1). Spread of pain, i.e. reporting pain in at least one additional anatomic site at T2 compared to T1, was reported by $31.6 \%(n=1329)$ if including subjects that reported no pain at T1, which may include subjects experiencing onset as well as spread of pain. Among those reporting at least one pain site at $\mathrm{T} 1$, but not five pain sites, $29.2 \%(n=874)$ experienced an increase in NPS (Additional file 1: Table S1). A decrease in NPS was observed for $29.1 \%(n=1224)$ of the full sample, and for $37.2 \%(n=1112)$ of those reporting $1-4$ pain sites at $\mathrm{T} 1$ (Additional file 1: Table S1).

\section{Dropout and attrition analyes}

Among invited subjects $(N=10274)$, non-response analyses showed that subjects aged 30-39 and 40-49 were more likely than others to return the questionnaire with completed information about all five pain sites at the first survey (ORs of non-response: $0.81,95 \%$ CI $0.69-0.95$ and OR 0.80, 95\% CI 0.68-0.94, respectively) (Table 1). Women were less likely to respond than men (OR 1.16 of non-response, 95\% CI 1.07-1.26) (Table 1).

Attrition analyses among the 6198 who responded to the first survey revealed that age groups 40-49 and 50-59 were less likely to drop out (i.e. more likely to also return information at T2), while those employed as technicians and associate professionals, clerks, service workers and shop and market sales workers, craft and related trades workers, and elementary occupations were more likely to drop out. Employees with the highest skill level, i.e. jobs reflecting more than 15 years of education, were least likely to drop out (Table 1 ).

\section{Adjusted own effects}

After adjustment for sex, age, skill level and T1 NPS, decreases in NPS were less likely for those reporting 
higher levels of emotional exhaustion (OR $0.8195 \%$ CI 0.69-0.95), mental distress (OR 0.69, 95\% CI 0.540.89), sleep disturbance (OR $0.87,95 \%$ CI $0.79-0.96$ ), tiredness (OR 0.82, 95\% CI 0.73-0.93), restlessness (OR 0.80, 95\% CI 0.69-0.92), headache intensity (OR $0.69,95 \%$ CI $0.54-0.89$ ), neck pain intensity (OR 0.64 , 95\% CI 0.56-0.73), shoulder pain intensity (OR 0.78 , 95\% CI $0.68-0.89$ ), and back pain intensity (OR 0.85 , 95\% CI 0.76-0.96).

Increased NPS (spread of pain) from baseline to follow-up was more likely for higher levels of emotional exhaustion (OR 1.34, 95\% CI 1.15-1.57), mental distress (OR 1.64, 95\% CI 1.28-2.10), feeling down and sad (OR 1.18, 95\% CI 1.06-1.31), sleep disturbance (OR 1.19, 95\% CI 1.07-1.31), tiredness (OR 1.24, 95\% CI 1.091.40), and headache intensity (OR 1.17, 95\% CI 1.041.32), and less likely for higher levels of surplus (OR $0.87,95 \%$ CI $0.80-0.95$ ). A higher number of pain sites at T1 was associated with higher likelihood of decrease (OR 1.33, 95\% CI 1.22-1.45) and lower likelihood of increase (OR 0.79, 95\% CI 0.72-0.87). Likelihood ratio tests suggested that entering predictors as categorical improved the models for the intensity of headache, shoulder pain, leg pain, back pain, and arm pain (see Additional file 1: Table S4). For pain in the leg, back, and arm the likelihood of decrease in the number of pain sites was elevated for subjects reporting light pain compared to no pain or moderate to severe pain, and for arm pain and leg pain, these statistically significant effects were not detected with the linear predictor, as can be seen in Table 2 .

The analyses of the degree of change can be seen in Table 3. They revealed that among those who experienced increases of NPS, more severe increases were predicted by emotional exhaustion (OR 1.34, 95\% CI 1.10-1.64), mental distress (OR 1.67, 95\% CI 1.222.30 ), anxiety (OR 1.40, 95\% CI 1.03-1.90), sleep disturbance (OR 1.29, 95\% CI 1.14-1.47), and headache intensity (OR 1.24, 95\% CI 1.06-1.46). On the other hand, having a lot of surplus predicted less severe increases for this group (OR 0.83, 95\% CI 0.75-0.92). For subjects experiencing decreases, a slower rate of decrease was predicted by higher levels of emotional exhaustion (OR 0.64, 95\% CI 0.51-0.80), mental distress (OR 0.45, 95\% CI 0.31-0.65), depression (OR $0.64,95 \%$ CI $0.51-0.80$ ), anxiety (OR $0.45,95 \%$ CI $0.29-0.67$ ), lower general self-efficacy (OR $0.77,95 \%$ CI 0.61-0.98), sleep disturbance (OR 0.80, 95\% CI 0.70-0.92), tiredness (OR 0.81, 95\% CI 0.68-0.96), restlessness (OR 0.76, 95\% CI 0.62-0.93), headache intensity (OR $0.83,95 \%$ CI $0.70-0.98$ ), neck pain intensity (OR $0.67,95 \%$ CI $0.55-0.81$ ), and back pain intensity (OR $0.79,95 \%$ CI $0.65-0.94$ ). A higher rate of decrease was predicted by having more surplus (OR
1.21, 95\% CI 1.08-1.35). A higher initial number of pain sites predicted a higher rate of decrease (OR 1.90, 95\% CI 1.71-2.12) and lower rate of increase (OR 0.71, 95\% CI 0.64-0.79). Table 3 also shows that all studied factors except general self-efficacy exhibited statistically significant associations with the number of pain sites reported by those subjects that reported the same number at both time points, with ORs ranging from $0.50,95 \%$ CI $0.43-0.59$ for job satisfaction to 9.15, 95\% CI 7.85-10.71 for neck pain.

\section{Mutually adjusted effects}

Regressions adjusted for all other studied factors revealed that the following factors remained statistically significant predictors: having a lot of surplus (for decrease NPS: OR 0.87, 95\% CI 0.78-0.97, for degree of increase: OR 0.84, 95\% CI 0.73-0.97), restlessness (for decrease NPS: OR 0.77, 95\% CI 0.62-0.96), sleep disturbance (for degree of increase: OR 1.24, 95\% CI 1.03-1.49), depression (for degree of increase: OR 0.69, 95\% CI 0.48-0.98), neck pain (for decrease NPS: OR $0.63,95 \%$ CI $0.53-0.76$, for degree of decrease: OR $0.61,95 \%$ CI 0.47-0.79), shoulder pain (for decrease NPS: OR $0.79,95 \%$ CI 0.66-0.93), back pain (for decrease NPS: OR $0.78,95 \%$ CI $0.66-0.92$, for degree of decrease: OR 0.73, 95\% CI 0.58-0.92) (Tables 4 and 5). Higher number of pain sites at T1 increased the likelihood of decrease (OR 2.04, 95\% CI 1.69-2.47), decreased the likelihood of increase (OR 0.69, 95\% CI 0.56-0.85), and increased the likelihood of faster decrease (OR 3.11, 95\% CI 2.45-3.98). Among subjects with sTable NPS, anxiety, surplus, tiredness, restlessness, and the intensity of pain in the neck, shoulder, arm, leg, and back were associated with the number of pain sites reported (ranging from OR 0.51, 95\% CI $0.29-0.88$ for anxiety to OR $6.85,95 \%$ CI $5.29-8.97$ for leg pain intensity).

\section{Discussion}

The present study supported the role of several psychological and physiological factors as influences on spread of pain and alleviation of multi-site pain. Emotional exhaustion, mental distress, sleep disturbance, tiredness and headache intensity appeared to affect the probabilities of both increased and decreased number of pain sites over 2 years. Restlessness, neck pain intensity, shoulder pain intensity, and back pain intensity seemed to influence decreases in NPS, while the experience of having a lot of surplus or feeling down and sad appeared to mainly influence the likelihood of spread of pain, by making it less likely and more likely, respectively. Moreover, depression and anxiety did not seem to directly influence whether or not decrease or increase happened, but were nevertheless related to the rate at which it did. The initial number of reported pain sites predicted both pain decrease and increase. 
Table 3 Separate ordinal logistic regressions relating psychological factors and pain intensities at T1 to: 1) the number of pain sites among subjects reporting the same NPS at T1 and T2,2) the number of pain sites decreased among subjects that reported a higher number of pain sites at T1, and 3) the number of pain sites increased among subjects that a higher number of pain sites at $\mathrm{T} 2$

\begin{tabular}{|c|c|c|c|c|c|c|c|c|c|}
\hline \multirow{3}{*}{$\begin{array}{l}\text { Sub-sample: } \\
\text { Outcome variable: } \\
\text { T1 Predictor }\end{array}$} & \multicolumn{3}{|c|}{$\begin{array}{l}\text { Employees reporting stable number of } \\
\text { pain sites } \\
\text { (T1 NPS }=\text { T2 NPS) }\end{array}$} & \multicolumn{3}{|c|}{$\begin{array}{l}\text { Employees reporting decreased number } \\
\text { of pain sites } \\
\text { (T1 NPS > T2 NPS) }\end{array}$} & \multicolumn{3}{|c|}{$\begin{array}{l}\text { Employees reporting increased number } \\
\text { of pain sites } \\
\text { (T1 NPS }<\text { T2 NPS) }\end{array}$} \\
\hline & \multicolumn{3}{|c|}{ Number of pain sites } & \multicolumn{3}{|c|}{ Number of pain sites decreased } & \multicolumn{3}{|c|}{ Number of pain sites increased (spread) } \\
\hline & $\mathrm{N}$ & OR & $95 \% \mathrm{Cl}$ & $\mathrm{N}$ & OR & $95 \% \mathrm{Cl}$ & $\mathrm{N}$ & OR & $95 \% \mathrm{Cl}$ \\
\hline Emotional exhaustion & 1444 & 3.99 & {$[3.38-4.73]^{* * *}$} & 1080 & 0.64 & {$[0.51-0.80]^{* *}$} & 1162 & 1.34 & {$[1.10-1.64]^{* *}$} \\
\hline Mental distress (HSCL) & 1515 & 7.10 & {$[5.47-9.24]^{* * *}$} & 1124 & 0.45 & {$[0.31-0.65]^{* *}$} & 1208 & 1.67 & {$[1.22-2.30]^{* *}$} \\
\hline Depression (single item) & 1601 & 2.30 & {$[1.95-2.72] * * *$} & 1194 & 0.64 & {$[0.51-0.80]^{* * *}$} & 1286 & 0.99 & {$[0.79-1.24]$} \\
\hline Anxiety (single item) & 1598 & 3.05 & {$[2.33-4.00] * * *$} & 1192 & 0.45 & {$[0.29-0.67]^{* * *}$} & 1288 & 1.40 & {$[1.03-1.90]^{*}$} \\
\hline \multicolumn{10}{|l|}{ Psychological well-being } \\
\hline "Had a lot of surplus" & 1541 & 0.58 & {$[0.53-0.62]^{* * *}$} & 1146 & 1.21 & {$[1.08-1.35]^{* *}$} & 1245 & 0.83 & {$[0.75-0.92]^{* *}$} \\
\hline "Felt down and sad" & 1536 & 1.64 & {$[1.47-1.84]^{* * *}$} & 1147 & 0.90 & {$[0.78-1.04]$} & 1242 & 1.09 & {$[0.96-1.24]$} \\
\hline Dispositional optimism & 1578 & 0.60 & {$[0.52-0.70] * * *$} & 1175 & 1.15 & {$[0.93-1.41]$} & 1255 & 0.85 & {$[0.71-1.02]$} \\
\hline General self-efficacy & 1577 & 1.16 & {$[0.97-1.38]$} & 1177 & 0.77 & {$[0.61-0.98]^{*}$} & 1263 & 1.15 & {$[0.92-1.42]$} \\
\hline Job satisfaction & 1442 & 0.50 & $[0.43-0.59]]^{* * *}$ & 1068 & 1.19 & {$[0.96-1.47]$} & 1148 & 0.83 & {$[0.68-1.03]$} \\
\hline Sleep disturbance & 1537 & 1.90 & {$[1.73-2.10]^{* * *}$} & 1154 & 0.80 & {$[0.70-0.92]^{* *}$} & 1231 & 1.29 & {$[1.14-1.47]^{* *}$} \\
\hline Tiredness & 1606 & 2.50 & {$[2.21-2.82]^{* * *}$} & 1197 & 0.81 & {$[0.68-0.96]^{*}$} & 1287 & 1.15 & {$[0.98-1.35]$} \\
\hline Restlessness & 1604 & 2.12 & {$[1.83-2.46]^{* * *}$} & 1194 & 0.76 & {$[0.62-0.93]^{* *}$} & 1289 & 1.20 & {$[0.98-1.45]$} \\
\hline \multicolumn{10}{|l|}{ Pain intensity } \\
\hline Headache & 1608 & 3.04 & {$[2.67-3.46]^{* * *}$} & 1196 & 0.83 & {$[0.70-0.98]^{*}$} & 1292 & 1.24 & {$[1.06-1.46]^{* *}$} \\
\hline Neck pain & 1610 & 9.15 & {$[7.85-10.71]^{* * *}$} & 1197 & 0.67 & {$[0.55-0.81]^{* *}$} & 1293 & 1.04 & {$[0.86-2.35]$} \\
\hline Shoulder pain & 1610 & 8.70 & {$[7.44-10.22]^{* * *}$} & 1197 & 0.89 & {$[0.73-1.08]$} & 1293 & 0.83 & {$[0.66-1.03]$} \\
\hline Arm pain & 1610 & 6.01 & {$[5.07-7.17]^{* * *}$} & 1197 & 0.94 & {$[0.77-1.13]$} & 1293 & 0.80 & {$[0.59-1.05]$} \\
\hline Leg pain & 1610 & 4.47 & {$[3.82-5.26]^{* * *}$} & 1197 & 0.89 & {$[0.74-1.08]$} & 1293 & 1.04 & {$[0.82-1.32]$} \\
\hline Back pain & 1610 & 5.76 & {$[5.01-6.64]^{* * *}$} & 1197 & 0.79 & {$[0.65-0.94]^{* *}$} & 1293 & 1.12 & {$[0.93-1.35]$} \\
\hline Number of pain sites & - & - & - & 1197 & 1.90 & {$[1.71-2.12]^{* *}$} & 1293 & 0.71 & {$[0.64-0.79]^{* *}$} \\
\hline
\end{tabular}

${ }^{*} p<0.05,{ }^{* *} p<0.01,{ }^{* * *} p<0.001$

Note: All regressions with decrease and increase as outcome were adjusted for sex, age group, skill level, and T1 NPS. For these regressions subjects that reported no pain sites at $\mathrm{T} 1$ were included in the increase group and subjects reporting five pain sites at $\mathrm{T} 1$ were included in the decrease group

Limited knowledge exists about mechanisms of development of multisite musculoskeletal pain. We have not found longitudinal studies of psychological factors as predictors of spread and decline of musculoskeletal pain. Associations of headache and sleep disturbance with musculoskeletal pain have been reported, but the causal direction remains uncertain (see e.g. [16]). Our results indicate that headache plays a significant role in spread of musculoskeletal pain. Also, more intense back- or neck pain were robustly associated with subsequent change in NPS.

In a cohort study by Paananen and coworkers [28], short sleep duration $(<7 \mathrm{~h} /$ day) predicted persistence of multiple pain sites over a 2-years period among adolescents, and good quality sleep has been found to predict positive musculoskeletal health, i.e. having no pain and/or alleviation of musculoskeletal pain [1, 29]. Although sleep problems are commonly comorbid to musculoskeletal pain [30,31], a recent study by Anderson and colleagues [32] did not find that sleep disturbances predicted pain in fibromyalgia patients. However, the present study found that sleep disturbance and tiredness were significant predictors of NPS development [15, 33, 34].

Several psychological factors exhibited "adjusted own effects" on NPS change. Congruent with these findings, Mundal et al. [35] observed in a recent population-based study comprising 19000 individuals of a Norwegian county that both depression, anxiety, and sleep disturbances exhibited robust associations with the onset of chronic widespread pain over a period of 11 years.

However, in the current study none of the psychological factors predicted NPS change in the mutually adjusted analysis. For instance, emotional exhaustion and mental distress exhibited statistically non-significant effects in the final, fully adjusted model. Although associations between chronic pain and psychological distress, 
Table 4 Multivariable multinomial logistic regression with all predictors entered simultaneously and NPS decrease and increase as outcomes, with stable NPS as reference $(N=2199)$

\begin{tabular}{|c|c|c|c|c|}
\hline \multirow[t]{2}{*}{ T1 Predictor } & \multicolumn{2}{|c|}{ Decrease NPS } & \multicolumn{2}{|c|}{ Increase NPS } \\
\hline & $\overline{O R}$ & $95 \% \mathrm{Cl}$ & $\overline{O R}$ & $95 \% \mathrm{Cl}$ \\
\hline Emotional exhaustion & 0.92 & {$[0.71-1.19]$} & 1.00 & {$[0.78-1.34]$} \\
\hline Mental distress & 0.87 & {$[0.53-1.44]$} & 1.50 & {$[0.90-2.50]$} \\
\hline Depression (single item) & 1.20 & {$[0.93-1.56]$} & 0.95 & {$[0.73-1.25]$} \\
\hline Anxiety (single item) & 1.14 & {$[0.80-1.62]$} & 0.95 & {$[0.66-1.35]$} \\
\hline \multicolumn{5}{|l|}{ Psychological well-being } \\
\hline "Had a lot of surplus" & 0.87 & {$[0.78-0.97]^{* *}$} & 0.94 & {$[0.84-1.05]$} \\
\hline "Felt down and sad" & 1.06 & {$[0.91-1.24]$} & 1.07 & {$[0.91-1.26]$} \\
\hline Dispositional optimism & 1.05 & {$[0.87-1.27]$} & 1.07 & {$[0.88-1.30]$} \\
\hline General self-efficacy & 1.06 & {$[0.85-1.31]$} & 1.09 & {$[0.87-1.37]$} \\
\hline Job satisfaction (single item) & 0.96 & {$[0.80-1.15]$} & 1.14 & [0.93-1.39] \\
\hline Sleep disturbance & 0.96 & {$[0.84-1.10]$} & 1.07 & {$[0.93-1.23]$} \\
\hline Tiredness & 0.86 & {$[0.72-1.02]$} & 0.99 & {$[0.82-1.18]$} \\
\hline Restlessness & 0.77 & $[0.62-0.96]]^{*}$ & 0.95 & {$[0.76-1.18]$} \\
\hline \multicolumn{5}{|l|}{ Pain intensity } \\
\hline Headache & 0.90 & {$[0.77-1.04]$} & 1.09 & {$[0.94-1.26]$} \\
\hline Neck pain & 0.63 & {$[0.53-0.76]^{* * *}$} & 0.96 & {$[0.81-1.15]$} \\
\hline Shoulder pain & 0.79 & {$[0.66-0.93]^{* *}$} & 1.07 & {$[0.90-1.28]$} \\
\hline Leg pain & 0.90 & {$[0.76-1.07]$} & 1.01 & {$[0.83-1.22]$} \\
\hline Back pain & 0.78 & {$[0.66-0.92]^{* * *}$} & 1.04 & {$[0.88-1.23]$} \\
\hline Arm pain & 0.91 & {$[0.77-1.09]$} & 1.01 & {$[0.83-1.22]$} \\
\hline Number of pain sites & 2.04 & {$[1.69-2.47]^{* * *}$} & 0.69 & {$[0.56-0.85]^{* * *}$} \\
\hline
\end{tabular}

${ }^{*} p<0.05,{ }^{* *} p<0.01,{ }^{* * *} p<0.001$

Note: Subjects that reported either no pain sites or five pain sites at T1 were excluded since they could not experience decrease or increase of NPS, correspondingly. Adjustment was made for sex, age group, and skill level

anxiety and depression are thoroughly documented (see e.g. review by Manchikanti et al. [11]) the causal status of this relationship is not resolved. One study by Estlander and colleagues [36] found that psychological distress, depression and self-efficacy beliefs did not predict changes in pain frequency. The fact that a few predictors remained statistically significant in the final, mutually adjusted analyses of the current study convincingly may suggest a crucial role for these factors in the development of musculoskeletal pain conditions.

However, great caution should be exercised in inferring substantive non-significance for statistically nonsignificant factors in those analyses. There are many possible explanations for the loss of association or statistical significance for some predictors when entered into multivariable analysis with other predictors, confounding being only one. Certainly, the possibility remains that some predictors are influenced by other predictors in the model. Several of the included predictors were correlated, and the mutually adjusted regression represented an attempt to uncover "core predictors". However, in some instances the results may be hard to interpret. For instance, Table 4 suggests that having a lot of surplus lowers the likelihood of decrease in NPS, in contrast to Table 2, where it is associated with lowered odds of NPS increase. Thus it seems particularly pertinent to point out that the effect in Table 4 is conditional on effects of many conceptually similar factors as well as possible mediators of the relationship of interest. For instance, sleep problems is one indicator of mental distress incorporated as an item in the HSCL-10, the measure of psychological distress of the current study. The possibility that e.g. sleep problems represent an important mediating mechanism between several of the other independent factors and pain site development must be considered a viable explanation.

Back- and neck pain intensity at baseline predicted an increase in the number of pain sites from baseline to follow-up. Kamaleri and coworkers [37] found that multi-site pain at baseline was the most important predictor for an increase in number of pain sites 14 years later. Nevertheless, they also found that number of pain sites tended to remain stable over time, a finding supported by Gummesson and coworkers [38]. Several previous studies have reported that co-occurring pain in multiple musculoskeletal sites is common in working and patient populations $[31,39,40]$. The present study found that higher numbers of pain sites at baseline were associated with lowered risk of an increase in number of pain sites from baseline to follow-up. This may be partly due to regression towards the mean. Another possible explanation is that the 2-years span between baseline and follow-up is too short to detect spread of pain related to baseline pain. Although the present study showed that $29.2 \%$ experienced pain spread, for some subjects the increase may reflect fluctuating pain rather than the development of a condition characterized by multiple pain sites. Nevertheless, the current results support the notion that the intensity of current pain is a more reliable marker of risk of spread than the number of pre-existing pain sites.

There is strong evidence that specific psychosocial work factors and job satisfaction predict pain (e.g. [41-44]). Job satisfaction was not associated with pain spread in the present study. Intensity, onset, and spread of pain are, however, different endpoints and the pathogeneses of pain onset and spread may differ. Moreover, employees with high job satisfaction did indeed report fewer pain sites among subjects with stable NPS (see Table 3). Such results are of course equivalent to cross-sectional associations, but may nevertheless suggest that a relationship between job satisfaction and NPS exists although any changes in the number of pain sites induced by satisfaction with the job may not be detectable over a time period of two years. 
Table 5 Multivariable ordinal logistic regressions with all psychological factors and pain intensities entered simultaneously as predictors of: 1) the number of pain sites among subjects reporting the same NPS at T1 and T2 (N=1201), 2) the number of pain sites decreased among subjects that reported a higher number of pain sites at T1 (N=909), and 3) the number of pain sites increased among subjects that a higher number of pain sites at T2 $(N=963)$

\begin{tabular}{|c|c|c|c|c|c|c|}
\hline \multirow{3}{*}{$\begin{array}{l}\text { Sub-sample: } \\
\text { Outcome variable: } \\
\text { T1 Predictor }\end{array}$} & \multirow{2}{*}{\multicolumn{2}{|c|}{$\begin{array}{l}\text { Employees reporting stable number of } \\
\text { pain sites } \\
\text { (T1 NPS = T2 NPS) } \\
\text { Number of pain sites }\end{array}$}} & \multirow{2}{*}{\multicolumn{2}{|c|}{$\begin{array}{l}\text { Employees reporting decreased number } \\
\text { of pain sites } \\
\text { (T1 NPS > T2 NPS) } \\
\text { Number of pain sites decreased }\end{array}$}} & \multirow{2}{*}{\multicolumn{2}{|c|}{$\begin{array}{l}\text { Employees reporting increased numbe } \\
\text { of pain sites } \\
\text { (T1 NPS }<\text { T2 NPS) } \\
\text { Number of pain sites increased (spread) }\end{array}$}} \\
\hline & & & & & & \\
\hline & $\overline{\mathrm{OR}}$ & $95 \% \mathrm{Cl}$ & $\overline{\mathrm{OR}}$ & $95 \% \mathrm{Cl}$ & $\overline{\mathrm{OR}}$ & $95 \% \mathrm{Cl}$ \\
\hline Emotional exhaustion & 1.00 & {$[0.70-1.43]$} & 0.94 & {$[0.65-1.34]$} & 0.99 & {$[0.69-1.41]$} \\
\hline Mental distress (HSCL) & 0.88 & {$[0.45-1.71]$} & 0.57 & {$[0.29-1.11]$} & 1.16 & {$[0.59-2.29]$} \\
\hline Depression (single item) & 1.07 & {$[0.75-1.52]$} & 0.74 & {$[0.50-1.08]$} & 0.69 & {$[0.48-0.98]^{*}$} \\
\hline Anxiety (single item) & 0.51 & {$[0.29-0.88]^{*}$} & 0.63 & {$[0.34-1.11]$} & 1.48 & {$[0.97-2.23]$} \\
\hline \multicolumn{7}{|l|}{ Psychological well-being } \\
\hline "Had a lot of surplus" & 1.23 & $[1.06-1.43]]^{* *}$ & 1.04 & {$[0.89-1.21]$} & 0.84 & {$[0.73-0.97]^{*}$} \\
\hline "Felt down and sad" & 1.08 & {$[0.88-1.32]$} & 1.19 & {$[0.97-1.45]$} & 1.01 & {$[0.84-1.22]$} \\
\hline Dispositional optimism & 0.93 & {$[0.72-1.20]$} & 0.89 & {$[0.68-1.17]$} & 0.85 & {$[0.66-1.09]$} \\
\hline General self-efficacy & 1.03 & {$[0.76-1.38]$} & 0.89 & {$[0.65-1.21]$} & 0.95 & {$[0.72-1.25]$} \\
\hline Job satisfaction & 1.03 & {$[0.82-1.30]$} & 0.87 & {$[0.68-1.13]$} & 0.96 & {$[0.75-1.22]$} \\
\hline Sleep disturbance & 1.06 & {$[0.88-1.27]$} & 0.97 & {$[0.80-1.17]$} & 1.24 & {$[1.03-1.49]^{*}$} \\
\hline Tiredness & 1.28 & {$[1.00-1.64]^{*}$} & 1.09 & {$[0.84-1.41]$} & 0.94 & {$[0.74-1.18]$} \\
\hline Restlessness & 1.58 & {$[1.16-2.14]^{* *}$} & 1.07 & {$[0.78-1.46]$} & 0.90 & [0.68-1.19] \\
\hline \multicolumn{7}{|l|}{ Pain intensity } \\
\hline Headache & 0.92 & {$[0.75-1.12]$} & 0.93 & {$[0.75-1.15]$} & 1.14 & [0.93-1.39] \\
\hline Neck pain & 5.33 & {$[4.14-6.92]^{* * *}$} & 0.61 & {$[0.47-0.79]^{* * *}$} & 0.80 & {$[0.59-1.08]$} \\
\hline Shoulder pain & 6.78 & {$[5.26-8.82]^{* * *}$} & 0.89 & [0.69-1.15] & 0.75 & {$[0.54-1.01]$} \\
\hline Arm pain & 6.33 & {$[4.94-8.19]^{* * *}$} & 0.89 & {$[0.71-1.12]$} & 1.02 & {$[0.72-1.42]$} \\
\hline Leg pain & 6.85 & {$[5.29-8.97]^{* * *}$} & 0.85 & {$[0.67-1.07]$} & 0.79 & {$[0.58-1.05]$} \\
\hline Back pain & 5.85 & {$[4.61-7.48]^{* * *}$} & 0.73 & {$[0.58-0.92]^{* *}$} & 0.70 & {$[0.46-1.02]$} \\
\hline Number of pain sites & - & - & 3.11 & {$[2.45-3.98] * * *$} & 0.86 & {$[0.62-1.19]$} \\
\hline
\end{tabular}

${ }^{*} p<0.05,{ }^{* *} p<0.01,{ }^{* * *} p<0.001$

Note: The regressions with decrease and increase as outcome were adjusted for sex, age group, skill level, and T1 NPS

\section{Methodological considerations}

A strength of this study was the prospective panel design. However, generalizability may suffer from the moderate response rate (60.3\% at baseline). Also, dropout was associated with skill levels and age. However, due to non-random sampling the theoretical population for which the current results may be representative remains unknown, regardless of non-response and attrition. Nevertheless, the sample did encompass 63 different organizations and a wide variety of job types. In addition to nonresponse and attrition some information was lost due to item nonresponse (as evident from Tables 2 and 3, which report $\mathrm{N}$ for each separate analysis). The total amount of item missing data was only $2.2 \%$, but for three variables it was higher than $5 \%$ (job satisfaction 10.6\%, mental distress 5.8, and emotional exhaustion 9.5). Due to listwise deletion missing for some analyses was higher. However, voluntary and anonymous participation leaves room for individual motivational processes to affect response rates, and one concern many participants communicated was that the comprehensive questionnaire was time-consuming to complete. Hence, response rates declined gradually throughout the questionnaire, giving little reason to suspect specific selection based on item content.

Spread and reduction of musculoskeletal pain sites may have been underestimated in the current employee sample as morbidity rates are usually lower in the working population than in the general population [45]. This may also have affected the extent to which psychological health was associated with spread of pain, as individuals that were particularly vulnerable to the health effects of psychological factors may not have been employed and represented in the study. As can be seen in Additional file 1: Table S2, the distributions of several included 
factors were considerably skewed with few individuals reporting high levels of potentially challenging factors.

It is important to be aware of inherent limitations of the operationalization of NPS change in the current study. The variable was based on the difference of reported number of pain sites at T1 and T2, irrespective of which sites were reported. This implies, for instance, that subjects reporting the same number, but different location, of pain sites at the two time points would be labeled 'stable NPS', whereas they may actually have experienced onset of a new pain problem as a previous problem resolved. Furthermore, subjects that reported no pain sites at $\mathrm{T} 1$ and were thus excluded from the main analyses may have experienced pain prior to the 4 weeks referred to in the pain questions. For instance, if a subject reported no pain sites at $\mathrm{T} 1$ and two pain sites at T2 this may have been spread of pain. In Additional file 1: Table S3 regressions with NPS change direction are given both with and without subjects that reported no pain sites at T1. Results were very similar, with the main difference being more statistically significant results in the higher $\mathrm{N}$ sample. However, the current study could not capture all possible courses of pain site development, and future studies should incorporate such distinctions in study designs and analyses to obtain more nuanced information.

All data were collected by self-report questionnaires. Reporting bias (e.g., due to negative affect) influencing both exposure and outcome measures may inflate associations (common method bias (CMB)) [46]. However, if reporting bias were a major factor, one would expect indicators of negative affect, such as psychological distress, emotional exhaustion, and depression, to be core predictors of the outcome, whereas these factors were not significant predictors in the final analyses. Communicating respondent anonymity should also reduce CMB [46], and this was prioritized during the survey administration.

It is still unclear why some chronic pain disorders become widespread (e.g. fibromyalgia; [47]) while others remain localized to few musculoskeletal regions (e.g. low back pain). There may be a difference in pathophysiology of pain in different regions or there may be differences in individual predisposition or exposures that mediate spread of pain. Since the pathogenesis is obscure, one cannot know whether 2-years follow-up periods are optimal to detect predictors of pain spread. Pain spread may to a certain extent reflect normal fluctuations of pain [21] in different body regions among the healthy working population. Furthermore, mechanisms of pain spread may be different for individuals with chronic versus fluctuating pain, and from pain patients versus a healthy population. We do not know whether the respondents that reported having pain in the present study were patients with varying musculoskeletal pain disorders/chronic pain or not. The working population may not be comparable to groups with clinical pain diagnoses.

\section{Conclusion}

A range of psychological factors, sleep problems, and pain intensities predicted both spread of pain, reduction of number of musculoskeletal pain sites, and the degree to which increase and decrease occurred over a 2-years period. Further studies are warranted, and they should aim to clarify the mechanisms involved and the causal interplay that may exist between the various risk factors.

\section{Additional file}

Additional file 1: Table S1. Descriptives for NPS and $\triangle$ NPS. Table S2. Descriptives for all predictors. Table S3.Regressions with NPS "direction of change" as outcome for the final study sample and the full sample prior to executing selection criteria. Table S4. Regressions with NPS "direction of change" as outcome for categorized predictors. (DOCX 36 kb)

\section{Abbreviations}

CMB: Common method bias; HSCL: Hopkins Symptom Checklist;

ISCED: International Standard Classification of Education; ISCO: International Standard Classification of Occupations; LOT-R: Revised Life Orientation Test; NPS: Number of pain sites; OR: Odds ratio; REK: Regional Commitees for Medical and Health Research Ethics (Norwegian: Regional Etisk Komitè); T1: Time 1; T2: Time 2

\section{Acknowledgments}

The authors would like to thank the participants for their willingness to participate, and Bjørn Lau, Anne Lene Andersen, Shahrooz Elka, Margrethe Schøning, Jan S. Emberland, and Elisabeth Petersen for their assistance in the survey administration.

\section{Funding}

This study was funded by the Norwegian Research Council (grant number: 185209). The recipient of the funding was the National Institute of Occupational Health in Norway. The funders had no role in study design, data collection and analysis, decision to publish, or preparation of the manuscript.

\section{Availability of data and materials}

The license to collect and store the data from the Norwegian Data Inspectorate and the Regional Committees for Medical and Health Research Ethics stated specifically that de-identified data will be available only to collaborators with the National Institute of Occupational Health in Norway upon signing a declaration of confidentiality. Thus, data cannot be made publicly available, but may be available upon request. Any requests concerning the availability of the data should be directed to the project leader Stein Knardahl, stein.knardahl@stami. no/+47 23195210 or to the director Pål Molander pal.molander@stami.no/+47 23195110 at the National Institute of Occupational Health, Norway.

\section{Authors' contributions}

JOC, SK, SJ: substantial contribution to conception and design. SK, JOC: acquisition of data. JOC: analysis and interpretation of data. JOC, SK, SJ: drafting the article, revising it critically for important intellectual content, final approval of the version to be published.

\section{Competing interests}

The authors declare that they have no competing interests.

\section{Consent for publication}

Not applicable.

\section{Ethics approval and consent to participate}

The study was approved by the Regional Committees for Medical and Health Research Ethics in Norway, had a specific permission from the Data Inspectorate of Norway and was conducted in accordance with the World Medical Association Declaration of Helsinki. All study participants provided informed consent and data were de-identified for analyses. When accessing 
the web-based questionnaire by a personal login code, informed consent had to be confirmed before responding to the questionnaire. This consent procedure was approved by the Data Inspectorate and the Regional Committees for Medical and Health Research Ethics. Furthermore, the approval from the Data Inspectorate required strict procedures for keeping information confidential, and these procedures were communicated to employees before the survey in order to increase response probability and minimize strategic reporting.

\section{Publisher's Note}

Springer Nature remains neutral with regard to jurisdictional claims in published maps and institutional affiliations.

\section{Author details}

${ }^{1}$ Department of Work Psychology and Physiology, The National Institute of Occupational Health, Oslo, Norway. ${ }^{2}$ Oslo and Akershus University College of Applied Sciences, Faculty of Social Sciences, Department of Social Work, Child Welfare and Social Policy, Oslo, Norway.

Received: 20 October 2016 Accepted: 28 March 2017 Published online: 04 April 2017

\section{References}

1. Jones EA, McBeth J, Nicholl B, Morriss RK, Dickens C, Jones GT, Macfarlane GJ. What characterizes persons who do not report musculoskeletal pain? Results from a 4-year Population-based longitudinal study (the Epifund study). J Rheumatol. 2009;36:1071-7.

2. Hagen $K$, Linde M, Heuch I, Stovner LJ, Zwart J-A. Increasing prevalence of chronic musculoskeletal complaints. A large 11-year follow-Up in the general population (HUNT 2 and 3). Pain Med. 2011;12:1657-66.

3. Parent-Thirion A, Fernández Macías E, Hurley J, Vermeylen G. Fourth European Working Conditions Survey. Dublin: European Foundation for the Improvement of Living and Working Conditions; 2007. https://www. eurofound.europa.eu/sites/default/files/ef_publication/field_ef_document/ ef0698en.pdf.

4. Kamaleri Y, Natvig B, Ihlebaek CM, Benth JS, Bruusgaard D. Number of pain sites is associated with demographic, lifestyle, and health-related factors in the general population. Eur J Pain. 2008;12:742-8.

5. Haukka E, Kaila-Kangas L, Ojajarvi A, Miranda H, Karppinen J, Viikari-Juntura E, Heliovaara M, Leino-Arjas P. Pain in multiple sites and sickness absence trajectories: a prospective study among Finns. Pain. 2013;154:306-12.

6. Neupane S, Miranda H, Virtanen P, Siukola A, Nygard CH. Multi-site pain and work ability among an industrial population. Occup Med. 2011;61:563-9.

7. Natvig B, Ihlebæk C, Kamaleri Y, Bruusgaard D. Number of pain sites - a simple measure of population risk? In: Chronic Pain Epidemiology. Oxford: Oxford University Press; 2010. p. 71-82.

8. Woolf CJ. Central sensitization: implications for the diagnosis and treatment of pain. Pain. 2011:152:S2-15.

9. Arendt-Nielsen L, Graven-Nielsen T. Central sensitization in fibromyalgia and other musculoskeletal disorders. Curr Pain Headache Rep. 2003;7:355-61.

10. McDermid AJ, Rollman GB, McCain GA. Generalized hypervigilance in fibromyalgia: evidence of perceptual amplification. Pain. 1996;66:133-44.

11. Manchikanti L, Fellows B, Singh V. Understanding psychological aspects of chronic pain in interventional pain management. Pain Physician. 2002;5:57-82.

12. Leino P, Magni G. Depressive and distress symptoms as predictors of low back pain, neck-shoulder pain, and other musculoskeletal morbidity: a 10year follow-up of metal industry employees. Pain. 1993;53:89-94.

13. Magni G, Moreschi C, Rigatti-Luchini S, Merskey H. Prospective study on the relationship between depressive symptoms and chronic musculoskeletal pain. Pain. 1994;56:289-97.

14. Quartana PJ, Campbell CM, Edwards RR. Pain catastrophizing: a critical review. Expert Rev Neurother. 2009;9:745-58.

15. Alsaadi SM, McAuley JH, Hush JM, Maher CG. Prevalence of sleep disturbance in patients with low back pain. Eur Spine J. 2011;20:737-43.

16. Okifuji A, Hare BD. Do sleep disorders contribute to pain sensitivity? Curr Rheumatol Rep. 2011:13:528-34.

17. Haack M, Mullington JM. Sustained sleep restriction reduces emotional and physical well-being. Pain. 2005;119:56-64.

18. Edwards RR, Almeida DM, Klick B, Haythornthwaite JA, Smith MT. Duration of sleep contributes to next-day pain report in the general population. Pain. 2008;137:202-7
19. Kamaleri Y, Natvig B, Ihlebaek CM, Bruusgaard D. Does the number of musculoskeletal pain sites predict work disability? A 14-year prospective study. Eur J Pain. 2009;13:426-30.

20. Christensen JO, Knardahl S. Work and neck pain: a prospective study of psychological, social, and mechanical risk factors. Pain. 2010;151:162-73.

21. Steingrimsdottir OA, Vollestad NK, Roe C, Knardahl S. Variation in reporting of pain and other subjective health complaints in a working population and limitations of single sample measurements. Pain. 2004;110:130-9.

22. Kristensen TS, Borritz M, Villadsen E, Christensen KB. The Copenhagen burnout inventory: a new tool for the assessment of burnout. Work Stress. 2005;19:192-207.

23. Scheier MF, Carver CS, Bridges MW. Distinguishing optimism from neuroticism (and trait anxiety, self-mastery, and self-esteem): a reevaluation of the Life Orientation Test. J Pers Soc Psychol. 1994;67:1063-78.

24. Schwarzer RJ, Johnston M. Generalized Self-Efficacy scale. In: Weinman J, Wright S, Johnston M, editors. Measures in health psychology: A user's portfolio Causal and control beliefs. Windsor: NFER-NELSON; 1995. p. 35-7.

25. Derogatis LR, Lipman RS, Rickels K, Uhlenhuth EH, Covi L. The Hopkins Symptom Checklist (HSCL): a self-report symptom inventory. Behav Sci. 1974;19:1-15.

26. Strand $\mathrm{BH}$, Dalgard OS, Tambs $\mathrm{K}$, Rognerud M. Measuring the mental health status of the Norwegian population: a comparison of the instruments $\mathrm{SCL}$ 25, SCL-10, SCL-5 and MHI-5 (SF-36). Nord J Psychiatry. 2003;57:113-8.

27. R Core Team: R. A language and environment for statistical computing. Vienna: R Foundation for Statistical Computing; 2014.

28. Paananen MV, Taimela SP, Auvinen JP, Tammelin TH, Kantomaa MT, Ebeling HE, Taanila AM, Zitting PJ, Karppinen JI. Risk factors for persistence of multiple musculoskeletal pains in adolescence: a 2-year follow-up study. Eur J Pain. 2010;14:1026-32.

29. Davies KA, Macfarlane GJ, Nicholl BI, Dickens C, Morriss R, Ray D, McBeth J. Restorative sleep predicts the resolution of chronic widespread pain: results from the EPIFUND study. Rheumatology (Oxford). 2008;47:1809-13.

30. Lentz MJ, Landis CA, Rothermel J, Shaver JL. Effects of selective slow wave sleep disruption on musculoskeletal pain and fatigue in middle aged women. J Rheumatol. 1999;26:1586-92.

31. Hagen EM, Svensen E, Eriksen HR, Ihlebaek CM, Ursin H. Comorbid subjective health complaints in low back pain. Spine (Phila Pa 1976). 2006;31:1491-5.

32. Anderson RJ, McCrae CS, Staud R, Berry RB, Robinson ME. Predictors of clinical pain in fibromyalgia: examining the role of sleep. J Pain. 2012;13:350-8.

33. Nicassio PM, Ormseth SR, Kay M, Custodio M, Irwin MR, Olmstead R, Weisman $\mathrm{MH}$. The contribution of pain and depression to self-reported sleep disturbance in patients with rheumatoid arthritis. Pain. 2012;153:107-12.

34. Vleeshouwers J, Knardahl S, Christensen JO. Effects of psychological and social work factors on self-reported sleep disturbance and difficulties initiating sleep. Sleep. 2016;39:833-46.

35. Mundal I, Gråwe RW, Bjørngaard JH, Linaker OM, Fors EA. Psychosocia factors and risk of chronic widespread pain: an 11-year follow-up study — the HUNT study. Pain. 2014;155:1555-61.

36. Estlander AM, Takala EP, Viikari-Juntura E. Do psychological factors predict changes in musculoskeletal pain? A prospective, two-year follow-up study of a working population. J Occup Environ Med. 1998;40:445-53.

37. Kamaleri Y, Natvig B, Ihlebaek CM, Benth JS, Bruusgaard D. Change in the number of musculoskeletal pain sites: a 14-year prospective study. Pain. 2009:141:25-30.

38. Gummesson C, Isacsson S-O, Isacsson A, Andersson H, Ektor-Andersen J, Östergren $\mathrm{P}-\mathrm{O}$, Hanson B. The transition of reported pain in different body regions - a one-year follow-up study. BMC Musculoskelet Disord. 2006;7:1-7.

39. IJzelenberg W, Burdorf A. Impact of musculoskeletal co-morbidity of neck and upper extremities on healthcare utilisation and sickness absence for low back pain. Occup Environ Med. 2004;61:806-10.

40. Haukka E, Leino-Arjas P, Solovieva S, Ranta R, Viikari-Juntura E, Riihimaki $\mathrm{H}$. Co-occurrence of musculoskeletal pain among female kitchen workers. Int Arch Occup Environ Health. 2006:80:141-8.

41. Christensen JO, Knardahl S. Work and back pain: a prospective study of psychological, social and mechanical predictors of back pain severity. Eur Pain. 2012:16:921-33.

42. Christensen JO, Knardahl S. Time-course of occupational psychological and social factors as predictors of new-onset and persistent neck pain: a three-wave prospective study over 4 years. Pain. 2014;155:1262-71. 
43. Hauke A, Flintrop J, Brun E, Rugulies R. The impact of work-related psychosocial stressors on the onset of musculoskeletal disorders in specific body regions: a review and meta-analysis of 54 longitudinal studies. Work Stress. 2011:25:243-56.

44. Hoogendoorn WE, Bongers PM, de Vet HC, Houtman IL, Ariens GA, van Mechelen W, Bouter LM. Psychosocial work characteristics and psychological strain in relation to low-back pain. Scand J Work Environ Health. 2001;27:258-67.

45. $L i C Y$, Sung FC. A review of the healthy worker effect in occupational epidemiology. Occup Med Oxford. 1999;49:225-9.

46. Podsakoff PM, MacKenzie SB, Lee JY, Podsakoff NP. Common method biases in behavioral research: a critical review of the literature and recommended remedies. J Appl Psychol. 2003;88:879-903.

47. Staud R. Evidence for shared pain mechanisms in osteoarthritis, low back pain, and fibromyalgia. Curr Rheumatol Rep. 2011;13:513-20.

Submit your next manuscript to BioMed Central and we will help you at every step:

- We accept pre-submission inquiries

- Our selector tool helps you to find the most relevant journal

- We provide round the clock customer support

- Convenient online submission

- Thorough peer review

- Inclusion in PubMed and all major indexing services

- Maximum visibility for your research

Submit your manuscript at www.biomedcentral.com/submit
Biomed Central 